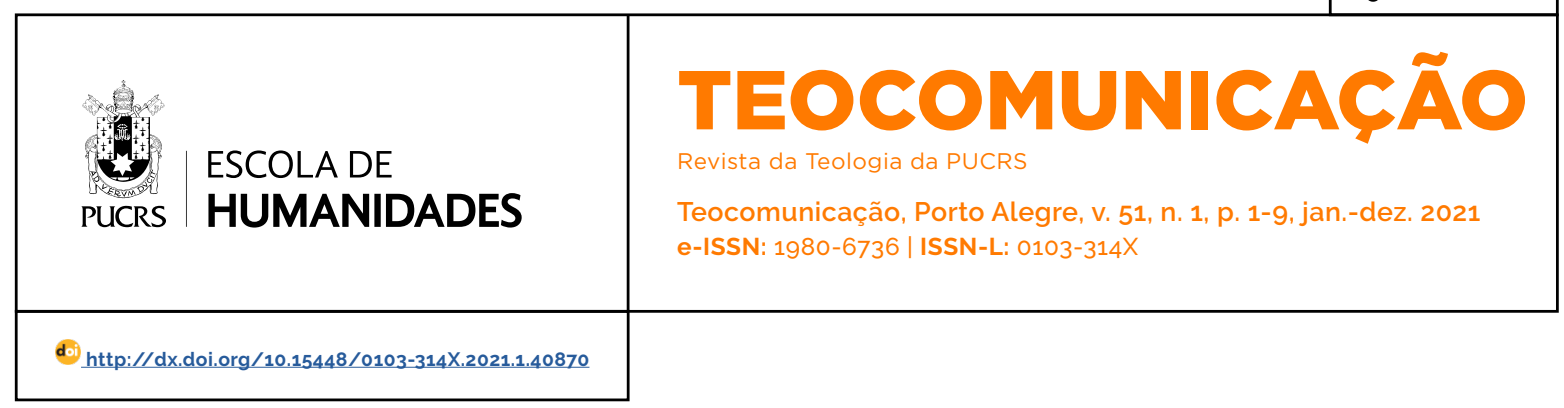

SEÇÃO: ARTIGOS LIVRES

\title{
El sentido contracultural de los episkópoi y diakónoi en Filipenses 1,1
}

The countercultural meaning of the episkópoi and diakónoi in Philippians 1,1

O significado contracultural do episkópoi e diakónoi em Filipenses 1,1

\section{Eduardo de la Serna ${ }^{1}$} orcid.org/0000-0002-6459-5678 edelasernag6@gmail.com

Recebido em: 30 abril. 2021. Aprovado em: 16 ago. 2021. Publicado em: 05 nov. 2021.
Resumen: La presencia de epískopos y diákonos en el saludo de la carta a los Filipenses es extraña dentro de las restantes cartas paulinas. No hay consenso entre los autores al respecto. El autor propone una lectura contracultural de ambos términos, en coherencia con otros, también importantes en la teología paulina. Especialmente considerando que Filipos es una colonia romana imbuida de ideologia imperial. Los visitantes a nuevas colonias (episkopoi) y los sirvientes (diakonoi) eran colectivos conocidos para los lectores, pero Pablo pretende subvertir el esquema, incluso presentándose él mismo, como "esclavo".

Palabras clave: Pablo. Episkopos. Diákonos. Contracultural. Colonia romana.

Abstract: The presence of episcopos and diakonos in the greeting of the letter to the Philippians is strange within the other Pauline letters. There is no consensus among scholars on this. The author proposes a countercultural reading of both terms, in coherence with others, also important in Pauline theology. Especially considering that Philippi is a Roman colony steeped in imperial ideology. Visitors to new colonies (episkopoi) and servants (diakonoi) were collectives known to readers, but Paul intends to subvert the scheme, even presenting himself as a "slave". Keywords: Paul. Episkopos. Diakonos. Countercultural. Roman colony.

Resumo: A presença de episcopos e diakonos na saudação da carta aos filipenses é estranha nas demais cartas paulinas. Não há consenso entre os autores sobre isso. $O$ autor propõe uma leitura contracultural de ambos os termos, em coerência com outros, também importantes na teologia paulina. Especialmente considerando que Filipos é uma colônia romana impregnada de ideologia imperial. Visitantes de novas colônias (episkopoi) e servos (diakonoi) eram coletivos conhecidos dos leitores, mas Paulo pretende subverter o esquema, apresentando-se mesmo como um "escravo".

Palavras-chave: Paulo. Episkopos. Diakonos. Contracultural. Colônia romana.

\section{Introducción}

Una simple mirada a las cartas auténticas de Pablo revela que luego de su presentación, como remitente, y, con frecuencia, de algún o algunos otros "que están conmigo" (Ga 1,2), el Apóstol menciona a su o sus destinatarios que son las comunidades, salvo el caso de la carta personal a Filemón (que, de todos modos, se amplia "a la iglesia de su casa", v. 2). Habitualmente, además de mencionar la localidad de la o las comunidades eclesiales, esta viene acompañada de una cualificación: "santos", habitualmente. Sus cartas tienen uno o varios destinatarios, aun- 
que, en ocasión, también presenta una apertura a varias iglesias de la región. En este sentido, es llamativo el saludo a los destinatarios de la carta a los Filipenses.

\section{La novedad de Filipenses 1,1}

Es un dato reconocido universalmente que la incorporación de los "syn episkópois kai diakónois" en el saludo de la carta de Pablo a los Filipenses representa una novedad para el resto de las cartas seguramente paulinas. La incorporación de este grupo provoca una serie de dificultades a la hora de entender a quiénes se refiere y el porqué de su incorporación en la misma.

1. Algunos niegan la presencia del texto en los manuscritos más antiguos. Con prudencia Theodore C. Skeat analiza el fragmento faltante (vacat) en el papiro Chester Beatty ( $\left.\mathrm{P}^{46}\right)$ : calculando el tamaño (unos $208 \mathrm{~mm}$ ) llega a la conclusión que algo se ha omitido (no más de 35 letras). Y si bien es una posibilidad que la referencia mencionada no se encontrara en el original, también es posible que falte por "homoioteleuton" (salto involuntario) que puede ser a causa de la repetición de tois (v.1) o también de pasê (vv.3.4), en cuyo caso se habrian omitido una cantidad de letras semejantes. $Y$ concluye que es evidente que una de estas "omisiones ha de haber ocurrido, pero es imposible decidir cual" y que la omisión de "syn episkópois kai diakónois" representa solo una posibilidad entre otras, por lo tanto, el resultado es "non liquet" (SKEAT, 1995, p. 12-15).

2. En esa misma línea de pensamiento hay que notar que algunos manuscritos, versiones y Padres presentan integrado "synepiskópois" (B², $D^{2}, K$, algunos minúsculos, it ${ }^{r}$ arm, Crisóstomo, Casiodoro, Teofilacto, Eutalio) algo que no es habitualmente aceptado como original, dada la cantidad y calidad de los manuscritos que sostie- nen la variante habitual, asimismo se ha de notar que la posibilidad parece ligada a "problemas de organización eclesial" ajenas a Pablo, además que cabria esperar que - en ese caso - se añadiera "syndiakónois" (FOCANT, 2016, p. 72).

3. Otros autores, como Wolfgang Schenk, niegan que el par "episkópos" y "diákonos" pertenezca a la carta original ya que habria sido incorporado al unirse las cartas originales. Como varios autores, Schenk sostiene que Pablo escribió tres cartas a los filipenses y que al unirse estas tardiamente - en tiempos de las cartas Pastorales - en una sola edición, se habría incorporado el par de co-destinatarios ${ }^{2}$.

4. Una de las preguntas clave es por qué Pablo incorpora los "episkópois" y "diakónois" en el saludo. Desde Juan Crisóstomo, muchos escritores interpretan que estos eran los responsables de recolectar la ayuda que Pablo recibirá en la prisión, a la cual se alude en 4,10-20 (la que muchos consideran "carta A") (FRIEDRICH, 1972, p. 103). Sin embargo, es de notar que nada se dice de ellos en ese fragmento, como seria de esperar. ${ }^{3}$

5. Hay consenso, en general, en evitar interpretar estos grupos a la luz de los ministerios que encontramos en los escritos más tardíos, como las cartas Pastorales, y, más aún, a la luz de los liderazgos posteriores de obispos y diáconos. Ya la traducción de los términos es problemática, precisamente por eso. En algunas versiones encontramos los términos tradicionales (obispos y diáconos)4 ${ }^{4}$, en otras se prefiere mantener la transliteración ("epískopos" y "diákonos"). Con sensatez, Camille Focant afirma que asi transliterada "lleva a la falsa idea de que se trata de un término técnico", por lo que prefiere "ministros establecidos para vigilar y para servir" (FOCANT, 2016, p. 72), lo que parece sensato salvo que parecieran demasiadas palabras para traducir una sola.

\footnotetext{
2 Lo sostiene SCHRENK, 1984. Y luego del comentario critico de KOPERSKI, 1992, p. 331-367 (la referencia a los episkopos y diákonos se encuentra en VV.130-131; aunque - como Schenk lo señala - la autora no ha analizado esta mención ya que su comentario es estrictamente lingüístico). Destaquemos que son muchos los autores que ven en Filipenses la recopilación de más de una carta (entre los que nos contamos), pero pocos interpretan la referencia como una glosa post-paulina a la luz de las cartas Pastorales.

3 Cf. WITHERINGTON III, 2011, p. 49; FABRIS, 2000, p. 47.

4 Asi, "obispos y diáconos": Biblia del Peregrino, Latinoamericana, Reina Valera, TOB; "Los que presiden" / episcopos y diáconos: Libro del pueblo de Dios, Biblia de Jerusalén. Extrañamente, COMBLIN, 1988, p. 27, utiliza "episcopos y diáconos" en su comentario, en el texto se mantiene "obispos y diáconos" siguiendo "nuestra Reina Valera", como se dice en nota. MACDONALD, 1994, p. 306, utiliza "inspectores y ministros"
} 
6. Otros autores, como Gordon Fee (1995, p. 66-69; 2004, p. 112-113), interpretan que seguramente deberia haber dichos "lideres" en todas las comunidades paulinas, pero solo aquí Pablo los nombra en razón de las "fricciones" que surgen en la comunidad (cf. 4,2-3). Puesto que el autor interpreta que las Pastorales son también de Pablo no ve demasiado paso del tiempo en la posible evolución del término.

7. Siendo que el término epískopos no se encuentra en Pablo, en más de una ocasión se lo interpreta a la luz de las otras recurrencias, ciertamente más tardias: así, la edición en fascículos de la Biblia de Jerusalén (Pierre Benoit) propone que los "epíscopos" son los encargados de dirigir o asistir la comunidad mientras los diáconos son sus asistentes 5 . No puede negarse, de todos modos, que la carta a los Filipenses es tenida por varios autores como tardia (escrita desde Roma), por lo que implica - para estos - una evolución en los "ministerios" (si Filipenses fuera la última carta del Apóstol, nos aproximamos en el tiempo a las Pastorales, especialmente si estas se ubican tempranamente).

El término diákonos, en cambio, tiene alguna recurrencia paulina, tanto el verbo como el sustantivo. La expresa referencia a Febe, que además es calificada de prostatis de Pablo y de la comunidad de Cencreas, no es evidente en su significado, pero si manifiesta una cierta ministerialidad.

8. Ernest Best (1968, p. 374-376) propone que Pablo toma el término de una carta que los filipenses le enviaron previamente. Así, al referirse a él y a Timoteo como "esclavos" (douloi) les afirma a estos que según sea su actitud pueden ser o no "santos", es decir miembros de la comunidad, con lo que los cuestiona (por eso, afirma, el "con" es exclusivo).

9. Así, otro elemento en discusión es si la preposición "con" ha de entenderse de modo exclusivo (como lo hace Best) o de un modo inclusivo (O'BRIEN, 1991, p. 48). Y también se debate si el "y" (kai) que une episkópois con diakónois ha de entenderse como unitivo o como epexegético; es decir: si se dirige a dos grupos: a los episkópoi "y" también a los diakónoi o a uno solo: los episkó- pois " $y$ " (que son también) diakónois; ambas son gramaticalmente posibles.

Valga esta breve presentación de las diferentes opiniones y posibilidades para notar las diversas posibilidades que la doble referencia presupone, y las dificultades que dificultan acordar en su interpretación.

\section{Episkópois kai diakónois}

Hay algunos elementos que parecen importantes de señalar antes de intentar presentar algunos elementos para una mejor comprensión del texto.

En las cartas pastorales el término "episkopos" se encuentra en singular (1 Tim 3,2; Ti 1,7), mientras aqui se halla en plural y sin artículo. En 1 Pe se refiere, también en singular, a Cristo $(2,25)$ y en Hch 20,28 (ambos textos son sin duda tardios) a los "presbýteros". En los textos Pastorales, además, no se señala en qué consiste la función sino las condiciones para acceder a ella. Es interesante, asimismo, la cercanía de los textos señalados con la imagen "pastoral" (poiména / poimainô,1 Pe, Hch). Es dificil saber, por tanto, a qué tipo de responsabilidad o servicio se refiere el título, más allá de la raíz ligada a la vigilancia o supervisión. En 1 Pedro, por ejemplo, además de afirmar que Cristo es "pastor y guardián (episkopo)" alude al día de la "visita" (episkopês) de Dios $(2,12)$ y a la responsabilidad de "pastorear" y "vigilar" (episkopeô) el rebaño $(5,2)$. Sin embargo, como es evidente, todas estas imágenes son tardías, y no es sensato leer Filipenses 1,1 a la luz de ellas. En todo caso, es - a lo sumo - posible que un tema insinuado rudimentariamente en Filipenses, haya sido luego desarrollado en algunas comunidades de un modo más institucionalizado (GNILKA, 1987. p. 32-39; ORTIZ, 2008, p. 51-53).

Varios autores han destacado - y coincidimos con ellos - que, en las diferentes comunidades, Pablo señala diferentes ministerios o servicios de liderazgo o de organización. Asi en Tesalónica Pablo alude a los proïstaménous (los que presiden, 1 Tes 5,12; algo que también - en su casa - hace el paterfamilias, cf. 1 Tim 3,4.5), en Galacia hace 
referencia al "catequista" (6,6), en Corinto, después de haber resaltado la importancia de los apóstoles, profetas y maestros, señala una serie de "ministerios" (notar que el que "dirige" la comunidad está mencionado casi al final, 1 Cor 12,28) y en Romanos la presidencia (proïstaménous) es una de tantas acciones en la asamblea (12,8). Pablo se ve a sí mismo como "padre" de la comunidad ( 1 Tes 2,11; 1 Cor 4,15) y por tanto ejerce - y las cartas lo manifiestan - su rol en ese sentido; pero luego, deja que en cada una de ellas se vayan dando la organización que el Espíritu les inspira en cada ocasión (REUMANN, 2008, p. 86-89).

Si esto también lo hemos de afirmar de los episkopos y diákonos, y, siendo, además, que Filipo es una colonia romana, como es sabido [Colonia Augusta Iulia Philippensis], todo indica - entonces - que el sentido que se ha de dar a los términos, ha de entenderse en clave romana, no judía. Esto es importante ya que la imagen de los "vigilantes" (mebaqqer) se ha encontrado en la literatura esenia, tanto en el Documento de Damasco como en escritos de Qumrán; en ellos se ve un paso (en los textos más antiguos) de una forma más democrática a una forma más monárquica (GNILKA, 1987, p. 37), pero no parece que aporte mucho a la comprensión del uso de los episkopos en esta carta.

El término diákonos, en cambio, se encuentra también en la literatura paulina, tanto el sustantivo como el verbo. Pablo se presenta, como también Apolo, como "diákonoi" por medio de los cuales los corintios han creído (1 Cor 3.5); los diferentes ministerios (diakoniôn) enriquecen en su diversidad la comunidad $(12,5)$ y es una característica de la "casa de Estéfanas" estar al servicio (diakonian) de los santos. En la primera parte de 2 Corintios (1-7), Pablo resalta particularmente su ministerio (diakonía) y el ministerio de la nueva alianza $(3,3-6,4)$ y, notablemente, la colecta - a la que tanta atención Pablo dedica - es vista como una diakonía en favor de los "santos" (2 Cor 8,4.19.20; 9,1.12.13; Rom 15,25).

Pablo ve su misión como un "diaconado". En cuanto al uso del sustantivo, este es más limitado, pero ha de señalarse que además de Pablo (1 Cor 3,5; 2 Cor 3,6; 6,4), Cristo mismo es presentado como "diákonon" (Rom 15,8) y asimismo Febe, que es "patrona" de la comunidad de Cencreas, también lo es (Rom 16,1) sin que se indique qué tipo de servicio realiza.

\section{El texto de Fil 1.1}

Pablo y Timoteo, esclavos (douloi) de Cristo Jesús a todos los santos en Cristo Jesús que están en Filipos con (syn) episkópois y diakónois (Fil 1,1)

Como es habitual, Pablo empieza su carta a los Filipenses con una autopresentación acompañado de un co-remitente; como en muchos otros casos (2 Cor 1,1; 1 Tes 1,1; Flm 1) este es Timoteo. Sabemos, que, con frecuencia él lo acompañó en sus viajes. Y, también, en muchas ocasiones fue enviado por Pablo a visitar las comunidades (así ocurre en Tesalónica, Corinto, Filipos: 1 Tes 3,2; 1 Cor 4,17; 16,10; Fil 2,19). Se sabía que el enviado representaba en todo al que lo enviaba: actuaba y hablaba en su nombre. En las ocasiones en las que oficia de co-remitente se supone que se encuentra con Pablo (no necesariamente en la prisión, en este caso), ${ }^{6}$ aunque ciertamente, sea este y su autoridad, en singular, la que se comunica a los destinatarios. En varias cartas paulinas el uso del plural es motivo de debate, y parece razonable dar una respuesta según cada caso en particular. Timoteo es mencionado en la primera carta paulina (1 Tes 3,2) y en la última (Rom 16,21 ) y puesto que - como vemos - se lo menciona en otros momentos de su ministerio, hemos de señalar, sin duda, que se trata de uno de los más estrechos colaboradores del Apóstol quien lo llama "hermano" (1 Tes 3,2; 2 Cor 1,1; Flm 1), "colaborador" (1 Tes 3,2; Rom 16,21) y "amado" (1 Cor 4,17) ... Es de notar, además, que en 1 Tes 2,7 Pablo usa el plural hablando de "nosotros" y señala que son "apóstoles de Cristo", lo que pareciera incluir en este caso también a Timoteo.

La relación de Timoteo con Pablo es tan estrecha que, en el caso de Corinto, - donde hay 
adversarios a Pablo - él supone que aquel a quién habia enviado (pempô, 4,17) pueda ser mal recibido por algunos de la comunidad y pide que esté alli "sin miedo" y que "nadie lo desprecie" y que luego le sea "re-enviado" (propempô) en paz (1 Cor 16,10-11). Pablo presenta esta relación como de "padre-hijo" (Fil 2,22). Pero aqui manifiesta que él sabe que los filipenses, a diferencia de lo que ocurre en Corinto, sí que lo reconocerán $(2,22)$; por eso, en este caso, no teme enviarlo "pronto", "cuando vea" más claro cómo sigue su situación (2,23-24) en la prisión en que se encuentra.

A diferencia de lo que es frecuente en otras cartas (cf. Rom, 1 Cor, 2 Cor, Ga), Pablo no se presenta como "apóstol" sino exclusivamente como "esclavo" (doulos) de Cristo (cf. Rom 1,1; Ga 1,10). Es lo único que dice de sí mismo (y de Timoteo; no como en Rom y Gal donde si bien se ha presentado como esclavo, también resalta su apostolado). Siendo que "esclavo" pertenece al mismo campo semántico de "diákonos", aquí simplemente nos limitamos a notar su uso y la ausencia de otros títulos de "autoridad" de parte del remitente para con la comunidad, reservando para más adelante la referencia al "servicio".

La carta se dirige a "los santos" que están en Filipos. El término "santos" (apartado para la divinidad) tiene un origen evidentemente judio. Israel es - o debe ser - el "pueblo santo", como se ve particularmente en el "Código de Santidad" (Lev 17-26). Propiamente hablando, es el pueblo el que es "santo", la comunidad, la asamblea, la ekklêsía lo son. No es algo que se dice especificamente de un individuo o de un grupo aislado. A su vez, hay cosas que son de Dios, o que pertenecen a su ámbito, y por eso mismo son santas: es el caso de lo que ocurre con las escrituras [Rom 1,2], la ley [Rom 7,12], el templo [1 Cor 3,17], el olivo [= el pueblo, Rom 11,16] e incluso "el beso", que es el saludo propio de los miembros de la comunidad [1 Tes 5,26; 1 Cor 16,20; 2 Cor 13,12; Rom 16,16]. Con frecuencia Pablo, además, al concluir las cartas, saluda a, o envía saludo de parte de "los santos" (Fil 4,21.22; 2 Cor 13,12; Rom 16,15]. La carta a "los santos" de Filipos es, entonces, dirigida a toda la comunidad, como también ocurre en 2 Cor 1,1 y
Rom 1,7. Es importante señalar, de todos modos, que ellos son santos porque han sido "hechos santos" (= por Dios), cf. 1 Cor 1,2; 6,11 ya que la "santidad" es una vocación (1 Cor 1,2; Rom 1,7), un "llamado" tanto a judíos como a griegos (1 Cor 1,24) a estar separados "en Cristo".

Como se dijo, los santos lo son "en Cristo Jesús". Como se sabe, esta fórmula "en Cristo" es frecuente en Pablo. Ser / estar "en" Cristo indica una manera de presentar a Cristo como si se tratara de un ámbito, una especie de "lugar". La imagen pareciera bautismal; estar sumergidos "en Cristo", lo cual permite comprender que quien(es) está(n) en Cristo asume(n) o se "introduce(n)" en un ámbito eclesial. Como es habitual en Pablo, la eclesiología y la cristología se entremezclan. Pero a su vez, estas se unen con la antropología porque el ser humano es quien está "en Cristo", por tanto, en una comunidad. Y esto, a su vez, tiene una dimensión escatológica, ya que se trata de un don del Espíritu: "en un espíritu hemos sido bautizados para no formar sino un solo cuerpo" (1 Cor 12,13). "El que está en Cristo es una nueva creación" (2 Cor 5,17). Con mucha frecuencia, en Pablo, la cristología, la eclesiología, la antropología y la escatología se entremezclan y se funden pasando, Pablo, con toda espontaneidad de una a otra (SERNA, 2008, p. 51-85, especialmente p. 78-79). Estando, entonces, sumergidos, espiritualmente unidos con/en Cristo, los destinatarios filipenses son "santos", son pueblo.

Es a estos destinatarios a los que Pablo añade "episkópois y diakónois", lo cual debe ubicarse claramente en su texto y contexto. Sería anacrónico, como dijimos, pensar en ministros ordenados, tal como dichos servicios lo serán mucho más tardíamente (obispos y diáconos). Destaquemos, sin embargo, que ninguna lectura debería impedir comprender que la carta se dirige a toda la comunidad "con" estos destinatarios, no a ellos especialmente.

Es sabido que episkopos, de donde proviene el más tardio, obispos, se refiere a una actitud de vigilancia sobre o en la comunidad (o una parte de ella). En ocasiones, el Imperio Romano envia "vigilantes" a las nuevas colonias (BEYER, p. 599-622); ¿se está refiriendo aquí, Pablo, a un 
diferente tipo de vigilancia para una nueva manera de "ciudadanía"? ¿Hay una imagen contra-cultural anti-romana en el título? ¿Puede entenderse esta vigilancia dentro del contexto de los ciudadanos del Evangelio $(2,27)$ y ciudadanos del cielo $(3,20)$ ? No debería dejarse de lado que el término ciudadanía (politeuma) sólo se encuentra en esta carta en el Nuevo Testamento. Asi como en el Imperio Romano hay supervisores que visitan para garantizar que las nuevas colonias se organicen conforme a lo que se espera de buenos romanos, no debería descartarse que aqui se trate de aquellos que deben garantizar (supervisar, vigilar, cuidar, es decir episkopêô) que esta nueva comunidad viva conforme al Evangelio, que tenga la mirada puesta "en los cielos", es decir, no en Roma.7

Los servidores (diákonos) son, como se dijo, más conocidos en el Nuevo Testamento. En ocasiones, servidor y esclavo son sinónimos (cf. Lc 12,37); en este caso, Pablo y Timoteo se presentan a sí mismos como "servidores-esclavos" (doulos) y se dirigen a los santos como también a "servidores-diákonos". Pablo parece usarlas, aplicándolas a sí mismo, de un modo indistinto. Es posible, entonces, que Pablo esté aludiendo a los que tienen una actitud de responsabilidad y los que están al servicio de la comunidad, de un modo genérico.

Sin embargo, no ha de descuidarse que tanto "esclavos" (doulos) como "servidor" (diákonos) no han de entenderse en sentido placentero o agradable como ciertas lecturas "espiritualistas" lo admitirian. Son dos términos estigmatizados y muy mal mirados. Los términos de la raíz esclav--(doul---) denotan, más bien, una dependencia con respecto a un amo (kyrios), mientras los de la raíz serv--- (diakon---) (BEYER, p. 81-93) expresan una acción, pero a nivel social ambos términos se refieren a los estratos más bajos de la sociedad. Es de señalar que diakon--- sólo se encuentra 6x en el Antiguo Testamento de la Biblia griega (Est 4X, 1x en 1 Mac y Pry además 1x en 4 Macabeos) donde tenemos siempre el sustantivo "siervo", nunca el verbo "servir", el cual si es frecuente en el Nuevo Testamento (el sustantivo, 29x; toda la raiz se encuentra 100x). El término esclav---, en cambio, es más frecuente (812x). En general, como decimos, se menciona una relación (por ejemplo, "esclavo de..."). En ese sentido, el esclavo dice relación al amo, el servicio, en cambio, dice relación a aquello que se sirve, por ejemplo, "la mesa". Es importante tener en cuenta que, en el helenismo, para el cual la divinidad no es tenida como un "señor", el término no es utilizado en sentido religioso. En el AT, en cambio, se recurre con frecuencia a ser doul--- de YHWH o también a otros términos como es el caso de leitourg--- (como se dijo, no se utiliza diakon---). Nos encontramos, también, en un mismo campo semántico con otra raíz: humil--- (tapein---) el cual también es visto negativamente en el helenismo (humillar a alguien, oprimirlo) mientras que - al menos en ocasiones - en Pablo tiene connotaciones diferentes (2,3; 3,21; 4,12). Estar al "servicio" los unos de los otros no es algo que se espera o se considere valioso en el mundo greco-romano. Nuevamente parece que nos movemos en un ambiente contracultural. No es fácil estar de acuerdo con Régis Burnet que el uso de la categoria "esclavo" tiene por finalidad "atraer la simpatía de los destinatarios" proponiéndose como colaborador y no en una imagen de superioridad, ubicándose en un pie de igualdad. ${ }^{8}$ El término "esclavo", o la imagen de "servicio" es lo suficientemente desagradable como para no atraer ninguna simpatía sobre quienes lo utilizan o a quienes se le atribuye.

\section{Lo contracultural}

Platón señala que hay un servicio "que en nada se diferencia de los esclavos" ... nuestra costumbre, en cambio (señala el filósofo) es "entregar el servicio a las mujeres" (Leyes, VII, 805e)

Por esta razón decimos que todas las otras artes son serviles (douloprepeis), subalternas (diakonikàs) e innobles (aneleutherous) respecto al cuidado del cuerpo, y que la gimnasia y la medicina son, en justicia, las dueñas de ellas (PLATÓN, Gorgias, 518a). 
Sirvan estos ejemplos para mostrar que ni el servicio diaconal ni el ser esclavo son vistos de un modo positivo en el mundo greco-romano. En el mundo biblico, en cambio, como se dijo, ser "servidor / esclavo" de Dios sí es algo presentado de un cierto modo positivo (Moisés lo es, el pueblo lo es, cf. Ex 4,10; Dt 6,13) aunque de ninguna manera se espera esa actitud con respecto a otros. No se esclavizará a un hermano "porque fuiste esclavo en Egipto" (cf. Lev 25,39.42; Dt 24,7). La imagen, entonces, del servicio a los hermanos y hermanas es ciertamente cristiana. De todos modos, es importante reiterar que los términos no han de entenderse ni en un modo institucional, ni tampoco técnico; con epískopos y diákonos, entonces puede referirse a un grupo que tiene una responsabilidad en la comunidad, como un progreso en "dirección a las pastorales", no dentro de las mismas comunidades paulinas. ${ }^{9}$

Ahora bien... es importante reiterar que Pablo enfrenta con particular insistencia de un modo contracultural elementos importantes de la ideología y propaganda imperial: el emperador, es "hijo de Dios", como se ve fácilmente en la numismática, ${ }^{10}$ y su nacimiento o acceso al trono es visto como una buena noticia (euaggelia). ${ }^{11}$ Los ciudadanos del imperio han de ser "fieles" (fides, pistôs) al Emperador, ${ }^{12}$ y agradecidos a su magnificencia (gratia, jaris), ${ }^{13}$ la cual manifiestan en las asambleas de la ciudad (ekklesiai). ${ }^{14}$ Este reconocimiento al "salvador" es manifestarse agradecidos la "paz" que trae a toda la oikoumene. Pero este reconocimiento del Emperador supone reconocer su superioridad siendo clientes del supremo patrón al cual se lo exalta manifestando su poder y humillando a quienes no lo reconocen. Ser esclavo, servidor y humillado revela lo más bajo de la escala social, las antípodas del Emperador, algo para lo que "cabe" la cruz como única pena en caso de desobediencia o subversión (cf. 2,8). La centralidad de estos términos imperiales en la teología paulina nos ubica, indudablemente, a Pablo en un marco conflictivo. No ha de pensarse que se trata de un "militante anti imperial", pero sí como quien no duda en proponer un mundo alternativo, una nueva ciudadanía. ${ }^{15}$

En este contexto contracultural, el rol de los "episkopoi" y los "diakónoi" sin duda debe ser visto como conflictivo. Y permite entender mejor por qué Pablo (y Timoteo) no se presenta a sí mismo como "apóstol", como es habitual, sino como "esclavo" (algo que también dirá de Cristo, en esta carta, por cierto; cf. 2,7).

Esto, finalmente, afirmado claramente en una colonia romana (una "pequeña Roma", se la ha llamado) como es el caso de Filipos, no puede menos que ser provocativo sea cual fuere el rol o ministerio que los títulos supusieran. Y quizás ayude a entender por qué el subversivo Pablo fracasó frecuentemente en su intento de presentar la novedad del Evangelio.

\section{Conclusión}

La sorpresiva incorporación de los episkópois kai diakónois en el saludo de la carta a los Filipenses ha llevado a diferentes interpretaciones y explicaciones. Hay consenso, en general, que se debe evitar una lectura anacrónica en consonancia con las cartas Pastorales, y más aún, en sintonía con los ministerios eclesiásticos de obispos y diáconos, ciertamente mucho más tardíos. Tampoco parece sensato todo intento de omitirlos, ya sea por considerarlos un añadido posterior, o como faltante en los manuscritos.

No podemos ignorar varios elementos: aun cuando el discípulo de Pablo, autor de las cartas Pastorales, haga referencia a episkopos y a diákonos, es evidente que alli no se especifica en qué consisten estos diferentes servicios, hasta el punto que pareciera posible que se los pudiera identificar, salvo por el uso del singular (episkopos) y del plural (diakónoi); no es imposible, por ejem-

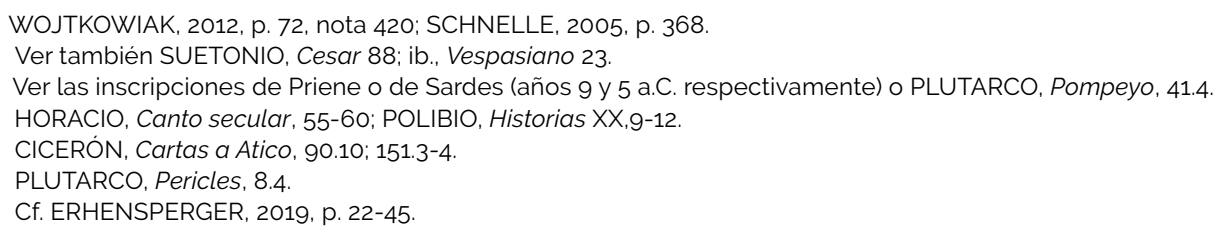


plo, que algún diákono ejerza (¿temporalmente?) como episkopo. En estas cartas es evidente que se alude a un tipo de servicio, sin que se especifique el modo y el tipo concreto de servicio. Retrocediendo en el tiempo, en 1 Pedro y Hechos se hace referencia al o a los epískopos, pero tampoco es claro el uso, ya que en el primero se aplica a Cristo mismo, mientras que en el segundo se hace referencia a algo que los presbiteros deben hacer. Todavía debemos retroceder bastante más en el tiempo para llegar a Filipenses, la primera vez que se menciona a los episkopos (en pluraly sin artículo) en el nuevo Testamento.

Siendo, como vimos, que Pablo acompaña los modos de organización que cada comunidad elige darse, todo indica que son los mismos filipenses los que los denominan episkópois kai diakónois y que no se trata de un modo de organización paulino. Pero en una ciudad que es una "pequeña Roma", ha de tenerse en cuenta el posible uso frecuentemente contracultural de muchos términos. Es en esta comunidad, concretamente, donde Pablo rescata el término ciudadanía (solo aqui en todo el Nuevo Testamento) ciertamente entendida con otro sentido al habitual: ciudadanía del Evangelio (1,27), de los cielos (3,20, es decir, donde está Cristo; donde tenemos reservado un edificio, 2 Cor 5,1; de donde viene Cristo a nuestra historia, 1 Cor 15,47; no en un sentido platónico, evidentemente). Es sensato que los habitantes de la colonia filipense que aceptaron el mensaje de Pablo, pretendan tener "vigilantes", supervisores que garanticen en la comunidad la fidelidad al Evangelio, a tener puesta la mirada en Dios y no en Roma.

Seguramente, para no centrarse en el Cesar. patrón de patrones, lo mejor es dirigir la mirada a Cristo, el que no se aferró a ser igual a Dios (como si hace el César, DIV-FI) sino que se humilló hasta ser esclavo y aceptar la muerte de los esclavos (2,7-8). El Cristo esclavo es el que lleva a Pablo (y Timoteo) a considerarse esclavo también él, y considerar servidores-diáconos a los que tienen responsabilidad en la comunidad.
Esto es doblemente significativo si el "kai" lo entendemos como epexegético (como lo hace Crisóstomo) refiriéndose a los vigilantes que son a su vez servidores, algo que es posible, aunque para la mayor parte de los estudiosos sea dudoso.

Lo cierto es que, si bien desconocemos el tipo de servicio o de oficio que los episkópois kai diakónois desempeñan, no hemos de dejar de lado dos elementos que parecen fundamentales: (1) que escribir a la comunidad de Filipos (entre el 55 y el 60 según se la ubique) es casi como escribir a Roma; y (2) que el uso de categorías contra culturales - al que Pablo recurre con frecuencia - parece aportar un sentido diferente a la lectura tradicional. La centralidad de la cultura romana no puede olvidarse, y la predicación paulina en ella, tampoco. Nada obsta que, más tardiamente (fines del s. I), la institucionalización empiece a presentarlos como ministerios, en un primer momento bastante genéricos en línea con la imagen "pastor-rebaño"; que más tardiamente - especialmente en las regiones de influencia paulina - empiecen a adquirir una mayor "jerarquización" (cartas Pastorales e Ignacio de Antioquia, primera parte del s. II) para finalmente ir adquiriendo una estructuración mayor, como se ve en la Traditio Apostolica (principios del s. III), antiguamente atribuida a Hipólito romano, donde ya se presenta claramente la estructuración episkopo-presbitero-diakono. Pero leer categorías de mitad del s. I a la luz de oficios del s. III es ciertamente anacrónico y, contribuye, una vez más, a interpretar mal a Pablo.

\section{Referencias ${ }^{16}$}

BENOIT, Pierre. Les Épitres de Saint Paul aux Philippiens, à Philémon, aux Colossiens, aux Ephésiens (BJ fasc.). 2. ed. Paris: CERF, 1953.

BEST, Ernest. Bishops and Deacons: Philipppians 1,1. In: CROSS, F. L. Studia Evangelica 4. Papers presented to the Third International congress on New Testament studies held at Christ Church, Oxford 1965. Part I: The New Testament Scriptures. Berlin: Akademie Verlag, 1968. p. 374-376. 
BEYER, Herman W. . In: KITTEL, Gerhard; FRIEDRICH, Gerhard; BROMILEY; Geoffrey W. (ed.). Theological Dictionary of the New Testament. Grand Rapids: Eerdmans, 1964. v. 2. p. 81-93.

BEYER, Herman W. пा $\mu$. In: KITTEL, Gerhard; FRIEDRICH, Gerhard; BROMILEY; Geoffrey W. (ed.). Theological Dictionary of the New Testament. Grand Rapids: Eerdmans, 1964. v. 2. p. 599-622.

BURNET, Régis. Epitres et lettres. ler-lle siècle: De Paul de Tarse à Polycarpe de Smyrne. Paris: CERF, 2003

COMBLIN, José. Filipenses. Buenos Aires: La Aurora, 1988.

DE LA SERNA, Eduardo. Aproximación a la teología paulina. Theologica Xaveriana, Bogotá, v. 58, n. 165, p. 51-85, ene./jun. 2008.

DOOLE, J. Andrew. Was Timothy in Prison with Paul? New Testament Studies, Cambridge, v. 65, n. 1, p. 59-77, jan. 2019.

ERHENSPERGER, Kathy. The Politeuma in the Heavens and the Construction of Collective identity in Philippians. Journal of the Jesus Movement in Its Jewish Setting, Jerusalem - Oslo - Chicago, v. 6, p. 22-45, 2019.

FABRIS, Rinaldo. Lettera ai Filippesi. Lettera a Filemone. Bologna: EDB, 2000.

FEE, Gordon D. Comentario de la Epistola a los Filipenses. Barcelona: CLIE, 2004.

FEE, Gordon D. Paul's letter to the Philippians. Grand Rapids: Eerdmans, 1995

FOCANT, Camille. La carta a los Filipenses. Salamanca: Sígueme, 2016.

FRIEDRICH, Gerhard. Filipenses. In: CONZELMANN, Hans; FRIEDRICH, Gerhard. Epistolas de la cautividad: Texto y comentario. Madrid: FAX, 1972. p. 91-171.

GNILKA, Joachim. Der Philipperbrief. 4. ed. Freiburg: Herder, 1987.

KOPERSKI, Viktoria. Textlinguistics and the Integrity of Philippians: A Critique of Wolfgang Schenk's Arguments for a Compilation Hypothesis. Ephemerides Theologicae Lovanienses, Louvain, v. 68, n. 4. p. 331-367, dic. 1992.

MACDONALD, Margaret Y. Las comunidades paulinas: Estudio socio-histórico de la institucionalización en los escritos paulinos y deuteropaulinos. Salamanca: Sígueme, 1994.

O'BRIEN, Peter T. Commentary on Philippians. Grand Rapids: Eerdmans, 1991.

ORTIZ, Pedro. Filipenses. Quetzaltenango. Guatemala: Universidad Francisco Marroquin, 2008.

REUMANN, John. Philippians: A New Translation with Introduction and Commentary. New Haven: Yale University Press, 2008.

SCHNELLE, Udo. Apostle Paul: His Life and Theology. Grand Rapids: Baker Academic, 2005.
SCHRENK, Wolfgang. Der Philipperbrief oder die Philipperbriefe des Paulus? Eine Antwort an V. Koperski Ephemerides Theologicae Lovanienses, Louvain, v. 70, n. 1, p. 122-131, abr. 1994.

SCHRENK, Wolfgang. Die Philipperbriefe des Paulus: Kommentar. Stuttgart: Kohlhammer, 1984.

SKEAT, Theodore Cressy. Did Paul write to 'Bishops and Deacons' at Philippi? A Note on Philippians 1:1. Novum Testamentum, Leiden, v. 37, p. 12-15, 1995.

SULLIVAN, M. Kathryn. A los Filipenses, Efesios, Colosenses y Filemón. Santander: Sal Terrae 1966.

WITHERINGTON III, Ben. Paul's Letter to thePhilippians: A Socio-Rhetorical Commentary. Grand Rapids: Eerdmans, 2011

WOJTKOWIAK, Heiko. Christologie und ethik im Philipperbrief: Studien zu Handlungsorientierung einer frühchristlichen Gemeinde in paganer Umwelt. Göttingen: Vandenhoeck \& Ruprecht, 2012.

\section{Eduardo de la Serna}

Doctor en Teología por la Pontificia Facoltà Teologica Teresianum, Roma, Italia; Profesor de la Escuela Bíblica Nuestra Señora de Sión, Buenos Aires, Argentina; profesor invitado de la Pontificia Universidad Javeriana (PUJ), Bogotá, Colombia.

Dirección para correspondencia

Eduardo de la Serna

Obispado de Quilmes

Av. Carlos Pellegrini, 3280, B1879DLB

Quilmes Oeste

Buenos Aires, Argentina

Os textos deste artigo foram conferido pela Poá Comunicação antes da publicação. 